\title{
О КОСНОМ, ЖИВОМ И МЕРТВОМ ВЕЩЕСТВАХ БИОСФЕРЫ, ПО В. И. ВЕРНАДСКОМУ И ПРЕДСТАВЛЕНИЯМ БИОГЕОЛОГИИ
}

\author{
(Представил О. Эйзен)
}

Вопрос генезиса каустобиолитов, в том числе горючих сланцев, с одной стороны, - сугубо частный вопрос, точнее часть науки о химии и технологии топлива и газа, с другой стороны, - комплексный, который невозможно решить без привлечения других наук, в первую очередь биологии, химии и геологии. Решение вопроса о генезисе каустобиолитов связано с особым сочетанием различных наук в единое целое - учение о биосфере, созданное В. И. Вернадским, с биокосными системами. Поскольку «зрелые» каустобиолиты представляют собой часть мертвого вещества Земли, то основное внимание ниже будет уделено судьбе мертвого вещества Земли.

В настоящее время широко обсуждаются, причем далеко не единодушно, вопросы, связанные с биосферой и некоторыми ее составными частями, такими как живое и биокосное вещества (биокосные тела или системы) $\left[{ }^{1-10}\right]$. Все возможные варианты неживого вещества (косного, мертвого или биогенного, космического) как составные части биосферы оставлены почти без внимания как В. И. Вернадским, так и другими учеными, принимающими участие в обсуждении или развивающими его учение о биосфере. Но без этих терминов-понятий невозможно дойти до понимания сущности роли живых организмов на нашей или любой другой планете, охваченной жизнью.

Дальнейшее обсуждение пойдет в следующем порядке. Вначале рассмотрим термины неживого вещества по В. И. Вернадскому и некоторые примеры использования их другими учеными. Выберем из них те термины, которые наиболее полно описывают биокосные системы. С их помощью дадим упрощенное расположение сфер, связанных с живым веществом Земли прямо или косвенно. Наконец, на одном частном примере покажем необходимость решительного перехода от традиционных, чисто геологических толкований биокосных систем к их биогеологическому толкованию.

В последнем и, с точки зрения самого автора, главном труде «Химическое строение биосферы Земли и ее окружения» [11] В. И. Вернадский отметил: «Биосфера не есть только так называемая область жизни. Это резко сказывается в ее веществе. Вещество ее состоит из семи глубоко разнородных частей, геологически не случайных». Он $\left[{ }^{11}\right.$, с. 58 60] перечисляет живое, биогенное, косное, биокосное вещества, вещества, существующие в радиоактивном распаде, рассеянные атомы и вещества космического происхождения. Из приведенного перечня только первым трем веществам в настоящее время уделяют внимание как полноценным составным частям биосферы. Биокосное вещество считается комплексной системой, состоящей из живого и косного вещества, космическое вещество входит в определение косного вещества [1, 2]. В. И. Вернадский чаще всего упоминает то живое, косное, биогенное и биокосное $\left[{ }^{11}\right.$, с. 127$]$, то только косное, живое и биокосное вещества в качестве 
составных частей биосферы $\left[{ }^{11}\right.$, с. 231]. В главе «Общее понятие о биосфере» рассматриваемой книги $\left[{ }^{11}\right.$, с. 58 - 59] указано, что живое вещество обозначает совокупность живых организмов, биогенное вещество является веществом, «создаваемым и перерабатываемым жизнью, т. е. живыми организмами», косное вещество есть вещество, «образуемое процессами, в которых живое вещество не участвует», и биокосное вещество «создается одновременно живыми организмами и косными процессами, представляя динамические равновесные системы тех и других». Далее, в главе «Живое вещество биосферы Земли как планетное явление», В. И. Вернадский пишет $\left[{ }^{11}\right.$, с. 231$]$ : «... в биосфере мы имеем дело с разными формами биосферного вещества: косного инертного малоактивного вещества, живого дисперсного, чрезвычайно химически и геологически активного, и биокосного вещества, являющегося закономерной структурой из живого и косного вещества».

Разные представления о неживом веществе в этих избранных цитатах Вернадского даны в таблице, из которой следует, что понятие косное вещество имеет разное толкование.

Типы вещества биосферы по [ $\left.{ }^{11}\right]$ *

\begin{tabular}{|c|c|c|c|c|c|}
\hline \multicolumn{2}{|c|}{$\begin{array}{l}\text { Xapakmep } \\
\text { seщесmba }\end{array}$} & $\begin{array}{l}\text { Граgац,ия } \\
\text { nо исхоgному }\end{array}$ & c. $58-60$ & c. 127 & c. 231 \\
\hline \multirow{3}{*}{ 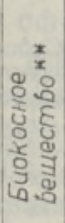 } & xuboe & scuboe & xuboe & xcuboe & muboe \\
\hline & \multirow{2}{*}{ rexcuboe } & биогенное & ઈиогенное & биогенное & \multirow{2}{*}{ КOCHOS } \\
\hline & & абиогенное & $\begin{array}{l}\text { kосное, } \\
\text { kосмичесkоe }\end{array}$ & KOCHOS & \\
\hline
\end{tabular}

* Рассеянные атомы и вещество в радиоактивном распаде не были включены; объяснения в тексте.

** В [1], [2] и других работах выделено как комплексное вещество.

Отметим еще, что в работах 20-х годов В. И. Вернадский сосредоточил свое внимание на обсуждении живого вещества в связи с мертвым [ $\left.{ }^{12}\right]$. В живое вещество он включил тогда и определенную часть неживого вещества (биогенного и косного). Это делает неправомерным утверждение: «В. И. Вернадский .... нигде не говорил о мертвом веществе, мертвой материи, равно как и о мертвой природе» [3]. Можно еще добавить, что термин «мертвая материя», согласно [ $\left.{ }^{4}\right]$, применялся В. И. Вернадским уже более чем 100 лет назад. Но как нужно относиться к утверждению, что косное вещество - не мертвое вещество, поскольку не было живым [3]? Хотя и мы придерживаемся того же мнения, но данные таблицы показывают, что это утверждение справедливо не для всех совокупностей примененных В. И. Вернадским терминов, так как в некотором контексте косное вещество может включать биогенное, а биогенное вещество когда-то было живым!

Целью вышеприведенного обсуждения было показать, что биосфера может быть описана отличающимися друг от друга системами терминов. Такое положение, по всей вероятности, характерно для всех отраслей науки в стадии становления и быстрого развития. Но однозначное толкование важнейших терминов биосферологии - вопрос первоочередной важности. Косным веществом следовало бы называть только 
По Bepнagckamy [6]. Mo Baccoebury [3]:

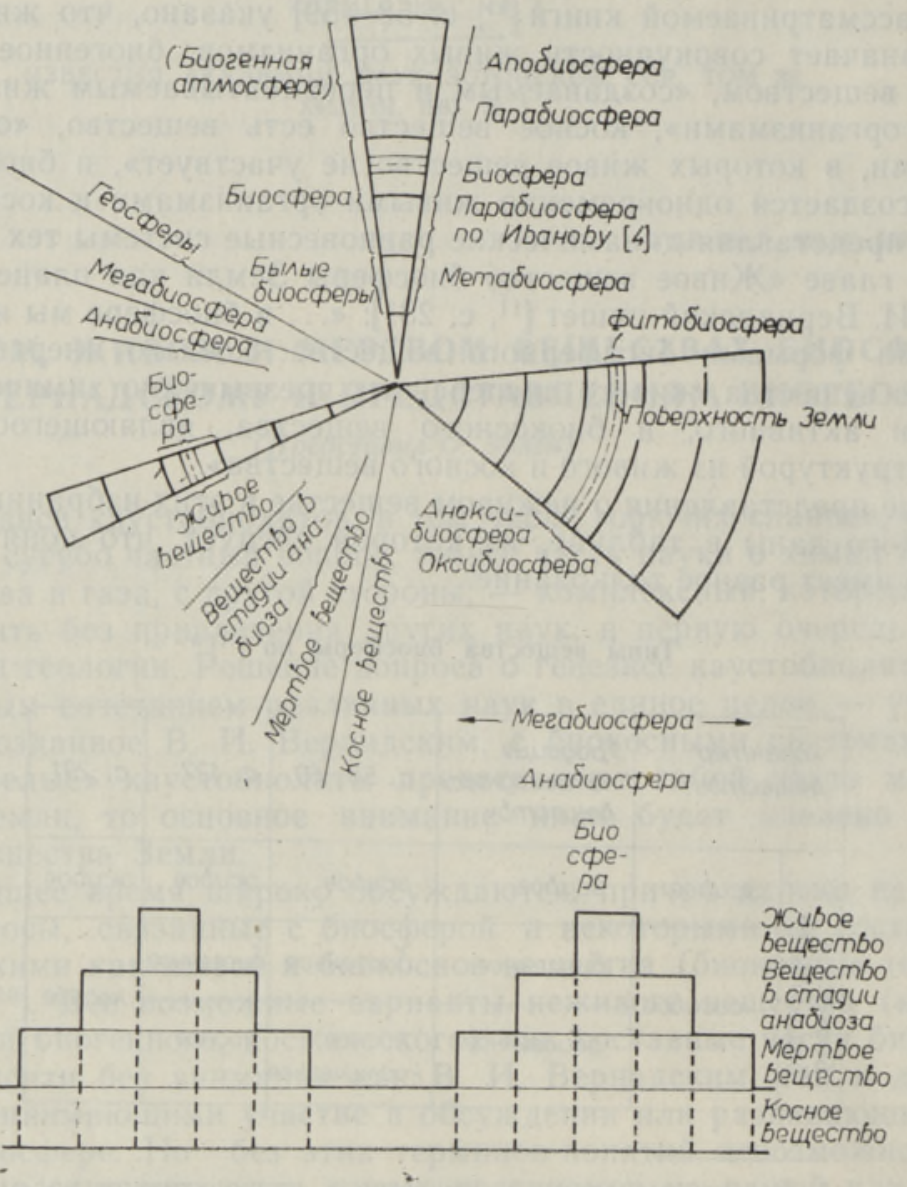

то вещество, которое никогда не было живым, т. е. вещество, которое существовало на Земле до появления и начала развития живых организмов и осталось нетронутым ими до настоящего времени, а также космическое вещество. Синонимом косного вещества служит вещество абиогенное. Живым веществом обозначается вещество живых организмов. Мертвым (синоним - биогенным ияи органогенным) следует называть вещество, которое было некогда живым, т. е. это все прижизненные выделения живых организмов, а также трупы и продукты их разложения. $\mathrm{K}$ неживому веществу относятся, таким образом, мертвое и косное. Итак, биокосные системы - это системы, состоящие как из живого, так и из неживого вещества. Самое большое биокосное тело это биосфера. Границы биосферы определяются наличием живого вещества.

Так это было определено и В. И. Вернадским [1'], к такому же выводу пришел Н. Б. Вассоевич [ $\left.{ }^{1}\right]$ при очень подробном анализе различных толкований понятия биосферы. Их взгляды на биосферу и ее окружение приведены в упрощенном виде на рисунке. Состав биосферы по В. И. Вернадскому мы уже рассматривали подробно (таблица). Былые биосферы по В. И. Вернадскому равнозначны с метабиосферой Н. Б. Вассоевича [ $\left.{ }^{1}\right]$. Они состоят из косного и мертвого вещества, причем распознают их по мертвому веществу, так как косное вещество является общим как для всех сфер Земли, так и для Вселенной. В атмосфере, которую и В. И. Вернадский считал биогенной, Дж. Хатчинсон [5] и Н. Б. Вассоевич ['] выделяют парабиосферу (она определяется наличием 
в ней заносимых ветром микроорганизмов, пыльцы и спор, находящихся в состоянии покоя) и апобиосферу (определяется содержанием в ней кислорода, являющегося продуктом жизнедеятельности организмов). Известно мнение А. Н. Иванова [6] о выделении зоны парабиосферы и под биосферой, в литосфере, куда тем или иным путем могут проникнуть и там уцелеть некоторые микроорганизмы. Мегабиосферу можно и нужно разделять на отдельные изолированные друг от друга сферы, как это принято и делается до сих пор. Однако, к сущности понятия биосферы и роли живого вещества на Земле можно прийти только при уделении равного внимания всем составным частям биосферы. Возникновение и распространение живого вещества является процессом, который всегда сопровождается образованием мертвого вещества. Спрашивается, правомерно ли выделять только метабиосферу (былых биосфер) и апобиосферу на основании наличия мертвого вещества, зная, что мертвое вещество сопутствует и парабиосфере, и, согласно учению В. И. Вернадского, самой биосфере, образуя таким образом компактную сферу? Подобно тому, как живое вещество определяет границы биосферы, и мертвое вещество должно быть принято в качестве критерия для определения границ большой биосферы, т. е., по Н. Б. Вассоевичу, мегабиосферы, которую можно назвать и тафосферой.

Теперь обратимся к особому состоянию живого вещества - к его нежизнедеятельному состоянию в парабиосферах, по Дж. Хатчинсону [5] и А. Н. Иванову [6]. В этом состоянии живые организмы находятся и в самой биосфере. Таким образом, в природе существует еще одна компактная сфера - анабиосфера (от слова анабиоз), границы которой определяют живые организмы в нежизнедеятельных, качественно особых состояниях живых организмов. К этим состояниям живых организмов мы возвратимся при рассмотрении вопросов, связанных с диагенезом вещества.

Сферы распространения мертвого вещества, живых организмов в нежизнедеятельных состояниях и биосфера, проникают друг в друга и в сферу косного вещества (рисунок). Поэтому мертвое вещество определяет мегабиосферу (тафосферу), живые организмы в нежизнедеятельных состояниях - анабиосферу, и живое вещество - биосферу.

Несомненно, нужны разграничения и определения сфер внутри биосферы. Самая важная - та сфера (зона), где происходит фотосинтез. А. И. Перельман $\left[{ }^{7,8}\right]$ выделяет фитогеосферу и редусферу. Фитогеосфера (фитосфера) - это ландшафты суши и верхние слои воды морей и океанов, где происходит аккумуляция солнечной энергии. Ниже располагается редусфера. Н. Б. Вассоевич[1] настаивал на использонии вместо этих понятий терминов «фотобиосфера» и жмелабиосфера». А. В. Лапо $\left[{ }^{2}\right]$, в свою очередь, предложил применять вместо термина «мелабиосфера» термин «меланобиосфера».

Так как живые организмы определяют границы биосферы, то они должны, по существу, определять границы и внутри биосферы. К таким классам организмов могут принадлежать аэробные и анаэробные. Из класса аэробных организмов целесообразно особо выделить фотоавтотрофные. Аэробные, анаэробные и фотоавтотрофные организмы определяли бы соответственно границы оксибиосферы, аноксибиосферы и фитобиосферы (рисунок). Толщину фитобиосферы можно определять как фактическую глубину проникновения корневой системы высших растений, к которой прибавляется высота этих же растений. Для водоемов толщина фитобиосферы практически равняется глубине проникновения света. При отсутствии высших растений толщина фитобиосферы в литосфере (на поверхности суши и в донных отложениях) небольшая и определяется границами существования организмов, ведущих фактически фотоавтотрофный образ жизни. 
Несомненно, в дальнейшем нужно иметь в виду необходимость выделения еще двух сфер, связанных с вирусами: сферы вирусов в живых организмах и сферы вирусов вне живых организмов. Первая может занимать часть или всю биосферу, но ни в коем случае не выходит за ее пределы. О границах второй сферы, связанной с вирусами, трудно вообще что-либо сказать из-за малой изученности распространения вирусов в геосферах. По этой причине данные сферы на рисунке не приводятся.

Легко представить, что по мере погружения мертвого вещества оно все больше и больше выходит из-под влияния живых организмов, так как их численность и активность уменьшаются. Переход вещества фотоавтотрофных организмов - прямо или после прохождения пищевых цепей различной сложности - в мертвое вещество представляет собой предмет учения о диагенезе и захоронении органического вещества. Рассмотрим вначале понятие «захоронение».

Прежде всего следует отметить, что в настоящее время отсутствует единое общепринятое мнение по вопросу захоронения органического вещества, хотя он представляется актуальным для многих отраслей наук, например, геологии, почвоведения, органической геохимии, при изучении генезиса каустобиолитов и т. д. Остается неуточненным, является ли захоронение выходом осадков \&... из-под непосредственного воздействия среды осадконакопления (водной, воздушной)» в ходе осадконакопления $\left[{ }^{13}\right]$, или это значительно более позднее событие, связанное с переходом «... органических остатков из биосферы в литосферу», согласно палеонтологическому варианту захоронения, тафономией $\left[{ }^{14}\right]$, или переходом биокосных естественных тел в косные [ $\left.{ }^{2}\right]$. Но так как в биосферу входит и верхняя часть литосферы, переход из биосферы в литосферу остается непонятным, так же как и переход биокосных систем в косные, ибо вещество живых организмов биокосных систем превращается не в косное, а в биогенное (мертвое; неорганическое и/или органическое) вещество. Но отмершее органическое вещество уже в верхних слоях биокосных систем может в дальнейшем изменяться или оставаться неизмененным, например, часть биологических маркеров или ядерные части макромолекул, которые остались неизмененными в биокосной системе. Или, может быть, следует считать любое мертвое вещество захороненным с момента фиксирования его в осадке, независимо от того, какова его судьба при дальнейшем диагенезе.

Живые организмы не только создают органическое вещество, но и модифицируют его, частично перерабатывая его снова из мертвого вещества в вещество живых организмов. Поэтому захоронение органического вещества можно было бы рассматривать как захоронение фотоавтотрофных организмов и их фрагментов на уровне организма или на молекулярном или групповом уровне, либо как захоронение гетеротрофных организмов, в том числе деструкторов, либо захоронение аэробных и анаэробных организмов, уже заранее занимающих в биосфере определенное положение по вертикали. В конечном счете мертвое органическое вещество биосферы переходит в органическое вещество пара- и метабиосферы. Имея в виду, что захоронение обозначает или выход, или переход вещества, можно отметить разные уровни этих переходов: переход в осадочное образование, переход из оксибиосферы в аноксибиосферу, что приблизительно соответствует трактовке понятия «захоронение»в $\left[{ }^{13}\right]$, переход из биосферы в пара- и метабиосферу - в $\left[{ }^{2,14}\right]$, переход в зону метагенеза и так далее, так как даже выход органического вещества из-под непосредственного влияния живых организмов не является гарантией его сохранения. Однако достижение восстановительных условий вообще предпосылка сохранения органического вещества, в том числе палеонтологического. Из всех этих уровней захоронения качественно отличается от других переход органического вещества биокосных сис- 
тем в пара-и метабиосферу. Учение о захоронении - это учение о судьбе мертвого вещества в биокосных системах и в пара- и метабиосфере.

Но имеется еще одно учение, которое по существу также занимается судьбой мертвого вещества, - это учение о диагенезе: «Диагенез мыслится как этап физико-химического уравновешивания осадка, представляющего собой первоначально неравновесную физико-химическую систему, сильно обводненную и богатую органическим веществом как живым (бактерии), так и мертвым» [15].

Учение о диагенезе (в сугубо геологическом аспекте), согласно традициям, рассматривает живые организмы как агенты, оказывающие определенное влияние на неживое вещество осадочных образований. В практической экспериментальной работе живые микроорганизмы неотделяемы от биокосных систем без вреда для целостности неживой их части. Трудно поэтому судить о фактическом объекте исследования диагенеза. Биокосное вещество на первый взгляд можно строго разделить на живую и неживую части. Но иногда и исследование живых организмов возможно только после их смерти или предварительного умерщвления. Является ли такой лишенный жизни объект уже объектом геологии? Вопрос этот можно сформулировать более конкретно, опираясь на имеющиеся достижения в изучении состояния активной жизнедеятельности организмов [16-18]. Так, первым этапом нежизнедеятельного состояния организмов, неприспособленных к анабиозу в природных условиях, считается смерть клиническая, позднее переходящая в смерть биологическую, т. е. - уже необратимое состояние. Эта точка перехода в состояние биологической смерти для организмов, приспособленных к анабиозу в природных условиях, обозначает начало полного анабиоза, являющегося обратимым состоянием. Оба эти состояния - полный анабиоз и биологическая смерть - характеризуются полным прекращением жизнедеятельности организмов $\left.{ }^{18}\right]$. Биологическая смерть, однако, означает начало превращения «биомолекул» в «геомолекулы». Состояние же полного анабиоза, хотя и является состоянием полного прекращения жизнедеятельности, может при благоприятных условиях в течение сотен лет сохранять живой организм без какого-либо существенного изменения и таким образом обеспечить организмам или их зародышам возвращение в жизнедеятельное состояние.

При сушке проб, взятых из биокосных систем, и подготовке их к анализу, живые организмы, находящиеся в этих пробах, умерщвляются и/или переходят в стадию анабиоза. Анабиоз, имеющий место при сушке, называется ангидробиозом. В аналитической практике распространен метод замораживания проб, взятых из донных отложений. Анабиоз, вызванный охлаждением, называется криптобиозом [19]. Отметим еще, что нежизнедеятельное состояние аэробов, вызванное снижением концентрации (хотя временным, сезонным) кислорода ниже уровня, необходимого для поддержания окислительного метаболизма, классифицируется как аноксибиоз. Состояние же микроорганизмов, при котором процессы обмена протекают очень медленно, называется иногда преданабиозом $\left[{ }^{16,17}\right]$. Молекулы органических веществ, выделенные при анализе из организмов, находящихся в стадии клинической смерти или анабиоза, - не что иное как молекулы живых организмов. Практически невозможно судить о принадлежности многих типичных биомолекул к живым организмам осадков или к их мертвому органическому веществу. То же самое можно сказать и относительно других биокосных систем. Мертвое органическое вещество или геоорганическое вещество в зоне диагенеза постоянно пополняется новыми молекулами за счет живых организмов.

О сохранности каких-либо молекул, свойственных живым организмам, можно с уверенностью говорить лишь тогда, когда, например, специфи- 
ческие только для фотоавтотрофных организмов молекулы определяются в зоне, расположенной значительно ниже зоны их обитания. Так как живые организмы состоят и из неорганического вещества $\left[{ }^{20}\right]$, при изучении диагенеза неорганических веществ не может остаться неучтенным и факт наличия в биокосных системах, наряду с мертвым и косным неорганическим веществом, неорганического вещества живых организмов (бионеорганическое вещество). Пока все методики анализа биокосных систем направлены на то, чтобы удалить живые организмы до начала анализа, например $\left[{ }^{16,21}\right]$. Это удается только для макроорганизмов и их частей (корни растений и др.).

Из этого следует, что геологические процессы в пределах биосферы и мегабиосферы (тафосферы) уже не являются чисто геологическими. Это подтверждается и стремлением геологов и философов выделить геологическую форму движения материи как промежуточную между химической и биологической формами. Для нашей Земли, можно, таким образом, выделить геологическую, биогеологическую, а также техногеологическую стадии развития. Выделение в рамках геологии раздела биогеологии заострило бы внимание на различиях между чисто геологическими процессами и геологическими процессами, происходящими в пределах биосферы и мегабиосферы (тафосферы).

Основываясь на работах по изучению органического вещества в докембрийских осадочно-метаморфических породах, А. В. Сидоренко и C. А. Сидоренко $\left[{ }^{10}\right]$ указали на тенденцию развития биогеохимии в биогеологию - в науку, «изучающую роль организмов в формировании земной коры». На Всесоюзном совещании по геохимии углерода (Москва, декабрь 1981) академик А. В. Сидоренко еще раз поднял вопрос о биогеологии. Но в биосферологизации геологии не менее актуально особое выделение учения о биокосных системах, какими, например, являются современные донные отложения и современная кора выветривания. Изучение их - основополагающее как для учения о раннем диагенезе каустобиолитов, так и для всей биогеологии.

\section{Л И Т Е Р А Т У Р А}

1. Вассоевич Н. Б. Различное толкование понятия биосферы. - В кн.: Исследование органического вещества современных и нскопаемых осадков. М., 1976, 381-399.

2. Лапо А. В. Следы былых биосфер. М., 1979.

3. Дылис Н. В. Учение В. И. Вернадского о биосфере и его значение для развития биогеоценологии. - Бюлл. о-ва испытат. природы, Отд. биол., 1978, 83(I), $62-68$.

4. Казначев В. П. Вопросы диалектики природы в работах В. И. Вернадского. - Вопр. филос., 1981, № 8, 100-108.

5. Хатчинсон Дж. Биосфера. - В кн.: Биосфера. М., 1972, 9-25.

6. Вассоевич Н. Б., Иванов А. Н. К истории учения о бносфере. - В кн.: Методология и история геологических наук. М., $1977,57-94$.

7. Перельман А. Н. Геохимия ландшафта. М., 1975.

8. Перельман А. Н. Биокосные системы Земли. М., 1977.

9. Карякин А. В., Грибовская И. Ф. Эмиссионный спектральный анализ объектов биосферы. М., 1979.

10. Сидоренко A. В., Сидоренко С. А. Органическое вещество в докембрийских осадочно-метаморфических породах и некоторые геологические проблемы. - Сов. геол., 1971, № 5, 3-20.

11. Вернадский В. Н. Химическое строение биосферы Земли и ее окружения. М., 1965.

12. Вернадский В. И. Живое вещество. М., 1978.

13. Геологический словарь. М., 1978, 1, 254.

14. Ефремов И. А. Тафономия - новая отрасль палеонтологии. - Изв. АН СССР, сер. бнол., № 3, 405-413.

15. Страхов Н. М. Диагенез. - В кн.: Геологический словарь. М., 1978, 221-222.

16. Бекер M. E. О взаимосвязи биоса и преданабиоза микроорганизмов. - В кн.: Анабиоз и преданабиоз микроорганизмов. Рига, 1973, 13-22.

17. Бекер М. Е., Дамбере Б. Э., Рапопорт А. И. Анабиоз микроорганизмов. Рига, 1981. 
18. Голдовский А. М. Анабиоз. Л., 1981.

19. Crove, J. H., Cooper, A. F. Cryptobiosis. - Sci. Amer., 1971, 225, N 6, 30-36.

20. Lowenstam, H. A. Minerals formed by organisms. - Science, 1981, 211, N 4487, $1126-1131$.

21. Воробьева Л. А. Лекции по химическому анализу почв. М., 1978.

Институт химии

Академии наук Эстонской ССР

Гіоступила в редакцию 25/V 1982

\section{R. VESKI}

\section{ABIOGEENSEST, ELUS- JA SURNUD AINEST BIOGEOLOOGIAS JA V. I. VERNADSKI BIOSFÄÄRIOPETUSES}

Artiklis on täpsustatud biosfääriōpetuses olulisi termineid, on uudselt määratud biosfääri (elusaine levikuala) asukoht anabiosfääri (anabioosi seisundis olevate elusorganismide levikuala) ja tafosfääri (surnud aine levikuala) suhtes: biosfäär on ümbritsetud ja koosneb ka neid sfääre määravatest ainetest.

Artiklist selgub biogeoloogilise mõtlemisviisi arendamise vajalikkus nüüdissetete diageneesi käsitlemisel.

\section{R. VESKI}

\section{ON THE ABIOGENIC, LIVING AND DEAD MATTER IN BIOGEOLOGY AND IN V. I. VERNADSKY'S THEORY OF BIOSPHERE}

The use of terms abiogenic, living and dead matter by V. I. Vernadsky, creater of the doctrine of biosphere, and many scientists, advancing his study, is under discussion, A principally new approach to imagining the spheres accompanied by living matter is given. According to that, biosphere is permeated with and also surrounded by anabiosphere (derived from the Greek 'anabiosis') determined by the living matter (organisms) in a state of anabiosis. The anabiosphere is in its turn permeated with and surrounded by taphosphere (derived from the Greek 'taphos') determined by the dead matter. All these spheres are compact. Taphosphere is identical to megabiosphere of N. B. Vassoevich, which is, unlike taphosphere, a complex sphere consisting of biosphere, parabiosphere, apobiosphere, and metabiosphere. A need for fixed spheres determined by viruses is also discussed. The problem of dead matter burial and diagenesis in biolifeless (биокосных) systems consisting of lifeless matter and living microorganisms is considered.

A conclusion is drawn that a better understanding of the early stages of transformation in modern sediments depends greatly on the progress of biogeological thinking. 